\title{
A Lithium Iron Phosphate Reference Electrode for Ionic Liquid Electrolytes
}

\author{
Johannes Wandt, Junqiao Lee, Damien W.M. Arrigan, Debbie S. Silvester* \\ Curtin Institute for Functional Molecules and Interfaces \& School of Molecular and Life Sciences, Curtin \\ University, GPO Box U1987, Perth, WA 6845, Australia.
}

*E-mail: d.silvester-dean@curtin.edu.au; Fax: +61(8)92664699; Tel: +61(8)92667148

\begin{abstract}
We report on the development of a very simple and robust reference electrode suitable for use in room temperature ionic liquids, that can be employed with planar devices. The reference electrode is based on $\mathrm{LiFePO}_{4}$ (LFP), a common cathode material in Li-ion batteries, which is air and water stable. The reference electrode can be drop-cast onto a planar electrode device in a single step. We demonstrate that very low $\mathrm{Li}^{+}$-ion concentrations (millimolar or below) are sufficient to obtain a stable and reproducible LFP potential, thus making physical separation between the reference and working electrode unnecessary. Most importantly, the LFP potential is also entirely stable in the presence of oxygen and only shows a very small drift (less than $10 \mathrm{mV}$ ) in the presence of hydrogen gas, while the potential of a platinum pseudo-reference electrode is shifted more than $800 \mathrm{mV}$. This is the first time that such a stable reference electrode system for ionic liquids has been implemented in miniaturized, planar electrode devices.
\end{abstract}

\section{Keywords}

Reference electrode; room temperature ionic liquids; lithium iron phosphate; planar electrode devices

\section{Introduction}

Room temperature ionic liquids (RTILs) are a very interesting class of solvent offering unique properties. Their non-volatility and intrinsic ionic conductivity makes RTILs ideal electrolytes for both fundamental electrochemical studies and various applications, especially electrochemical sensing.[1,2] A major challenge of RTIL electrolytes is the lack of a simple and reliable reference electrode.[3] Most electrochemical studies in RTILs rely on bare Pt or Ag wires as pseudo-reference electrodes. The main advantage of such a pseudo-reference electrode is its simplicity, but its potential depends upon surface or electrolyte impurities and is therefore not well defined [4]. This leads to potential drifts over time and hampers reproducibility and comparability between different experiments [5-8]. Ferrocene can be added at the end of an experiment for calibration purposes [3,8,9], but its relative low solubility [9], moderate volatility [10] and non-innocent nature in the presence of analyte species [8] must also be considered. Additionally, this "post-calibration" method may not be suitable for anything other than 
simple voltammetric experiments - for example, constant-potential methods, such as long-term chronoamperometry, where potential shifts can occur during the experiment.

To solve this problem, several groups have developed stable reference electrodes for RTILs utilizing redox couples like $\mathrm{Ag} / \mathrm{AgCl}$ [11], $\mathrm{Ag} / \mathrm{Ag}^{+}$[12-14], $\mathrm{Ag} / \mathrm{Ag}_{2} \mathrm{~S}$ [15] and ferrocene/ferrocenium $\left(\mathrm{Fc} / \mathrm{Fc}^{+}\right)$[7]. In most of these designs, the reference electrode is placed in a separate compartment which is ionically connected with the sample solution by a salt bridge (e.g. glass-fiber filter [7] or glass frit $[12,13,15]$ ). On the one hand, this physical separation is necessary to prevent influencing the electrochemistry at the working electrode by ion cross-over from the reference electrode (even $\mathrm{Ag} / \mathrm{AgCl}$ is somewhat soluble in RTILs [16]). On the other hand, it makes these designs more complicated, rendering them unsuitable for planar electrode devices which would otherwise be very promising platforms for medical and environmental lab-on-a-chip systems [17] and electrochemical sensors [18] because of their small size and low cost.

The goal of this study is the development of a reference electrode for RTIL electrolytes with the following properties: i) a well-defined and reproducible potential, ii) a simple assembly suitable for miniaturized devices, iii) chemical stability towards air and moisture and iv) potential stability in the presence of oxidizing and reducing gases. The reference electrode is based on lithium iron phosphate (LFP) [19], a well-known cathode material used in Li-ion batteries, which can reversibly de/intercalate Li-ions:

$$
\mathrm{LiFePO}_{4} \rightleftharpoons \mathrm{Li}^{+}(\mathrm{sol})+e^{-}+\mathrm{FePO}_{4}
$$

The delithiation of $\mathrm{LiFePO}_{4}$ is a two-phase reaction with a stable potential over a very broad lithium content ( $\mathrm{x}$ in $\mathrm{Li}_{x} \mathrm{FePO}_{4}$ ), thus making it an ideal reference electrode material - it has already been used in Li-ion batteries and ion-selective electrodes [20-24] but not yet in voltammetric experiments in RTILs. The idea involves using a single compartment amperometric cell containing the working, counter and the LFP reference electrode without a separation or diffusion barrier (e.g. glass frit) in-between. The major advantage of this one-compartment approach is its simplicity - the LFP powder can be applied to the reference electrode substrate in a one-step drop-casting - and can be easily incorporated into a printing process for mass fabrication. There are two possible problems with this one-compartment approach because the working and the reference electrodes share the same electrolyte solution. Firstly, the potential of the LFP reference electrode depends on the Li-ion concentration in the electrolyte (see equation 1). The presence of a lithium salt, added to the electrolyte to define the LFP reference electrode potential, might impact the electrochemistry at the working electrode. Secondly, reactive analyte species (especially gases) can also reach the LFP reference electrode where they might alter the reference potential. In order to address these two issues, we focus on i) minimizing the Li-ion concentration necessary for a reproducible LFP potential and ii) investigating the influence of $\mathrm{O}_{2}$ and $\mathrm{H}_{2}$ gases on the stability of the LFP potential. 


\section{Experimental}

\subsection{Preparation of LFP reference electrode}

$\mathrm{LiFePO}_{4}$ (Clariant, Germany) was chemically delithiated to $\mathrm{Li}_{0.5} \mathrm{FePO}_{4}$ by stirring it in an $0.05 \mathrm{M}$ aqueous $\mathrm{K}_{2} \mathrm{~S}_{2} \mathrm{O}_{8}$ (Sigma Aldrich, $>99.0 \%$ purity) solution for a few hours [21]. Afterwards, an ink was prepared containing $93 \mathrm{wt}-\% \mathrm{Li}_{0.5} \mathrm{FePO}_{4}, 7 \mathrm{wt}$ \% polyvinylidene fluoride as polymer binder (PVDF, Kynar) and $n$ methyl-2-pyrrolidone (NMP, Sigmal Aldrich) as solvent (solid content $0.55 \mathrm{~g} \mathrm{~mL}^{-1}$ ). The ink was homogenized with a magnetic stirrer for 30 minutes and dropcast using an Eppendorf pipette onto a microchip containing three thin-film (150 nm thickness) platinum electrodes (ED-SE1-Pt, MicruX, Ovedio, Spain, see Figure 1a). The NMP solvent was evaporated at $50{ }^{\circ} \mathrm{C}$ in a fume hood; the LFP ink was stored in a freezer to prevent sedimentation and could be used for several months. For simplicity, the LFP coating covered all three electrodes on the device (see Figure 1b), while a separate chip was used for the working and the counter electrode (see section 2.2 for details).

\subsection{Electrochemical experiments}

The potential of the reference electrode was determined against the half-wave potential, $E_{1 / 2}$, of ferrocene/ferrocenium $\left(\mathrm{Fc} / \mathrm{Fc}^{+}\right)$, a common redox-couple used as an internal reference in voltammetry [25]. In preliminary experiments, we observed that the presence of ferrocene can alter the open circuit potential of a platinum pseudo-reference electrode. In order to properly assess the potential stability/instability of the platinum pseudo- and the LFP reference electrode, two microchips were used, as shown in Figure 1c. One chip (left side in Figure 1c) contained the working and counter electrodes (WE\&CE) and the other chip (right side in Figure 1c) the reference electrode (RE). The electrolyte, kept in place by a glassfiber filter (Whatman, Sigma-Aldrich), consisted of the ionic liquid $N$-butyl- $N$-methylpyrrolidinium bis(trifluoromethylsulfonyl)imide ([C $\left.\mathrm{C}_{4} \mathrm{mpyrr}\right]\left[\mathrm{NTf} \mathrm{f}_{2}\right]$, loLiTec, $\left.99.0 \%\right)$ and a fixed concentration of lithium bis(trifluoromethylsulfonyl)imide salt (Li[NTf 2$]$, Sigma-Aldrich, 99.95\%). Equal concentrations of $\mathrm{Li}\left[\mathrm{NTf}_{2}\right]$ were added to both sides to prevent the formation of a junction potential. The WE\&CE chip also contained $10 \mathrm{mM}$ ferrocene (Sigma-Aldrich, 99.0\%). After adding the electrolyte, a $6 \times 6 \mathrm{~mm}$ glass coverslip was placed on top of the glassfiber filter covering the WE\&CE chip in order to slow down the diffusion of $\mathrm{H}_{2}$ to the working electrode. This was necessary as $\mathrm{H}_{2}$ is oxidized in a similar potential region as ferrocene. The RE chip was not covered, allowing fast gas diffusion towards the reference electrode.

The microchips were contained in a sealed modified glass T-cell [26] which was continuously purged with high purity nitrogen (BOC gas, North Ryde, NSW, Australia, 99.9\%) and optionally also $1 \%$ vol. $\mathrm{H}_{2}$ (BOC, 99.9\%) or $20 \%$ vol. $\mathrm{O}_{2}$ (BOC, $99.0 \%$ ). The gases were diluted using the relative ratios of two massflow controllers, as described previously [26]. After the assembly, the cell was allowed to equilibrate under $\mathrm{N}_{2}$ flow for one hour before repeatedly measuring cyclic voltammograms every three minutes with a scan rate of $500 \mathrm{mVs}^{-1}$ (PGSTAT101, Metrohm Autolab). Figure 1d shows three selected voltammograms measured either in pure $\mathrm{N}_{2}$ or in the presence of $\mathrm{H}_{2}$ or $\mathrm{O}_{2}$. 

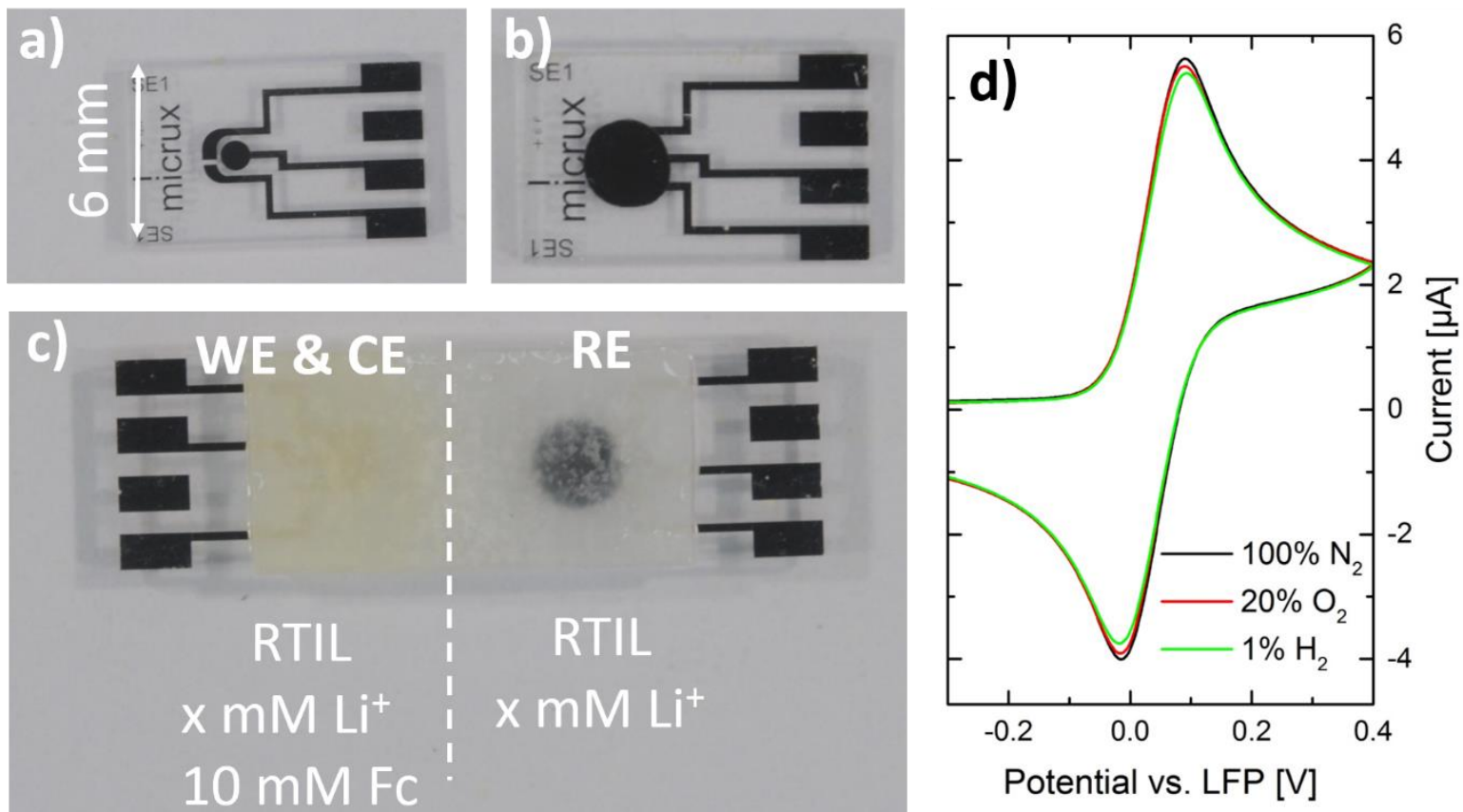

Figure 1 Microchip with platinum thin-film electrodes a) as received and b) with the LFP coating; c) set up consisting of two microchips, covered by a glassfiber separator containing the electrolyte (the dashed line indicates the boundary between the WE\&CE and the RE electrolyte). $x=0,0.1$, or $1 \mathrm{mM}$; d) Selected cyclic voltammograms $\left(500 \mathrm{mVs}^{-1}\right.$ ) showing the $\mathrm{Fc} / \mathrm{Fc}^{+}$redox couple in $\left[\mathrm{C}_{4} \mathrm{mpyrr}\right]\left[\mathrm{NTf} \mathrm{f}_{2}\right]$ in the presence of different gases.

\section{Results and Discussion}

Figure 2a shows the potential of the platinum pseudo- and LFP reference electrodes versus the $\mathrm{Fc} / \mathrm{Fc}^{+}$ potential after one hour of equilibration. The potential of the platinum pseudo-reference electrode, measured in the same set up shown in Figure 1c but without the LFP ink, changes by $>50 \mathrm{mV}$ in the initial 60 minute $\mathrm{N}_{2}$ period. Then, the potential increases by $200 \mathrm{mV}$ when purging with $20 \% \mathrm{O}_{2}$ and decreases by $800 \mathrm{mV}$ under $1 \% \mathrm{H}_{2}$. Interestingly, the platinum pseudo-reference electrode potential hardly recovers in the 30 minute $\mathrm{N}_{2}$ periods following the $\mathrm{O}_{2}$ and $\mathrm{H}_{2}$ flushing, which is an indication of the formation of Pt-O and Pt-H surface species [27]. The random potential drift under pure $\mathrm{N}_{2}$ and the significant potential change in the presence of $\mathrm{O}_{2}$ and $\mathrm{H}_{2}$ clearly demonstrates that platinum pseudoreference electrodes are not suitable for use in electrochemical gas sensors where stable potentials are required. In contrast, the potential of the LFP reference electrode was remarkably stable under these conditions (Figure 2a).

Figure $2 \mathrm{~b}$ shows an enlarged view of the LFP reference electrode potential region. The LFP potentials show the expected general trend that the potential increases with Li-ion concentration. Qualitatively, the potential difference between the $1 \mathrm{mM}$ and $0.1 \mathrm{mM} \mathrm{Li}\left[\mathrm{NTf}_{2}\right]$ solution of about $25 \mathrm{mV}$ is less than the Nernstian slope of $59 \mathrm{mV} / \mathrm{dec}$ for a one electron process (see equation 1). Such a non-Nernstian behavior has previously been reported for LFP-based ion selective electrodes at sub-millimolar Li-ion concentrations [22]. In our experiments, the potential of the LFP electrode in the presence of $0.1 \mathrm{mM}$ Li-ion is equivalent to that in the presence of the pure ionic liquid without added Li-ions. The most 
likely explanation is that the Li-ion impurity level in the neat ionic liquid is ca. $0.1 \mathrm{mM}$, which is not surprising considering that Li[NTf $]$ is used as stoichiometric reagent in the RTIL synthesis [28].
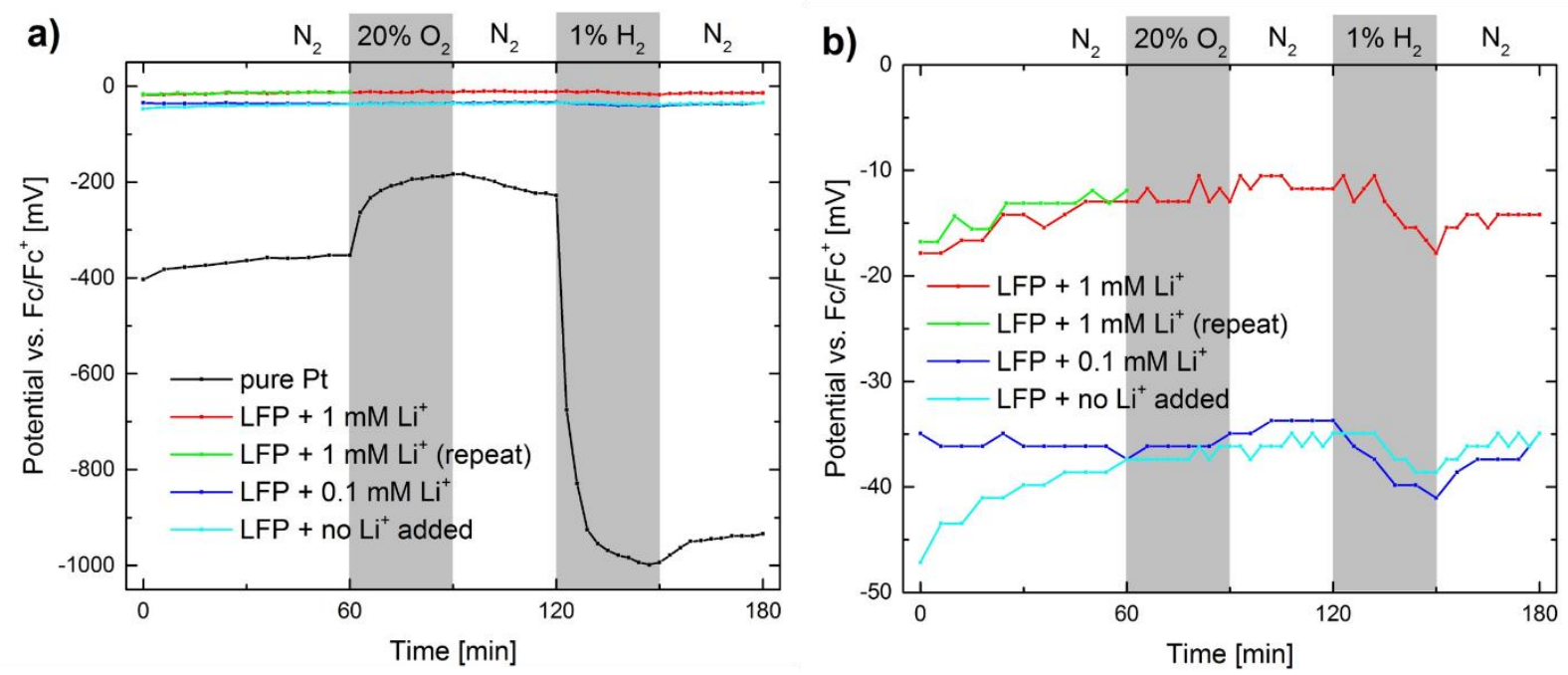

Figure $\mathbf{2}$ (a) Potentials of the platinum pseudo-reference electrode with neat ionic liquid and the LFP reference electrode with varying Li-ion concentrations. (b) an enlarged view of the LFP potential region from (a). Shaded areas indicate purging with $20 \% \mathrm{O}_{2}$ or $1 \% \mathrm{H}_{2}$, as indicated.

Let us now assess the potential stability of the LFP reference electrode over time. For most experiments, the LFP potential increases by about $5 \mathrm{mV}$ in the initial $\mathrm{N}_{2}$ period, which is a consequence of the removal of residual water from the ionic liquid electrolyte. The underlying reason is that the strong hydration of Li-ion favors the LFP delithiation (right hand side equation 1), thus making the $\mathrm{LiFePO}_{4} / \mathrm{FePO}_{4}$ redox couple less noble [29]. Water removal decreases this stabilizing effect and therefore increases the LFP potential. As a consequence, in ionic liquid electrolytes, the LFP potential can only be directly compared for experiments with a similar humidity level, otherwise a correction factor will be necessary.

While purging with $20 \% \mathrm{O}_{2}$, the potential of all LFP electrodes is entirely stable. During the $1 \% \mathrm{H}_{2}$ period, the potential of all LFP electrodes decreases by about $5 \mathrm{mV}$ in 30 minutes, irrespective of the Li-ion concentration. This potential decrease is negligible in comparison to the platinum pseudo-reference electrode ( $800 \mathrm{mV}$ ) and seems to be mostly reversible in the final $\mathrm{N}_{2}$ purging period.

Besides the above discussed stability, the reproducibility of the potential is another important aspect for reference electrodes. Figure $2 \mathrm{~b}$ shows two identical experiments with a $1 \mathrm{mM}$ Li-ion concentration (red and green curves) and the potentials match within $\pm 3 \mathrm{mV}$. For the reproduced experiment, which took place a few months after the first experiment, a fresh electrolyte, fresh microchips, a new batch of partially delithiated $\mathrm{Li}_{0.5} \mathrm{FePO}_{4}$ and a new LFP ink were prepared, which confirms that the whole preparation process is very reproducible.

The fact that a concentration of $1 \mathrm{mM} \mathrm{Li}$-ion is sufficient to obtain a reproducible potential removes the one compartment cell problem, because at such low concentrations, Li-ions are not expected to impact most electrochemical processes at the working electrode. This is especially true because $\mathrm{Li}^{+}$(in 
contrast to $\mathrm{Ag}^{+}$) is electrochemically inactive in a wide potential range because its reduction potential is extremely negative. The only problematic property of $\mathrm{Li}^{+}$is its high Lewis acidity, which is, for example, known to significantly affect the oxygen reduction reaction in aprotic electrolytes [30]. In such cases, it is possible to operate the LFP reference electrode without adding a lithium salt to the electrolyte which still gives a stable potential (see figure $2 b$ ), although this might negatively affect the reproducibility. Alternatively, an analogous sodium intercalation material (e.g. $\mathrm{NaFeO}_{2}$ ) [31] can be used instead because of the lower Lewis acidity of $\mathrm{Na}$-ions.

The good potential stability also in the presence of oxidizing and reducing gases like $\mathrm{O}_{2}$ and $\mathrm{H}_{2}$ in combination with the good reproducibility makes LFP a very good reference electrode material for use in ionic liquids. Additionally, it is compatible with common organic and aqueous electrolytes $[32,33]$ and is air stable [21]. Furthermore, LFP is commercially available and a one compartment design can be realized on miniaturized planar electrode devices with standard fabrication techniques.

\section{Conclusions}

In this study, we present a novel reference electrode for room temperature ionic liquids based on LFP. The LFP reference electrode potential is very reproducible and also stable in the presence of oxidizing and reducing gases like oxygen and hydrogen. We demonstrate that the LFP reference electrode can operate at very low Li-ion concentrations of $1 \mathrm{mM}$ or even without the addition of a lithium salt to the electrolyte. This could enable a simple one-compartment design suitable for miniaturized planar electrode devices in which the working, counter and reference electrode share the same electrolyte. The approach can also be extended for use with a LFP-coated platinum wire, dipped into the solution.

\section{Acknowledgments}

J.W. gratefully acknowledges the support of the German Academic Exchange Service (DAAD) scholarship. D.S.S. thanks the Australian Research Council for a Future Fellowship (FT170100315). 


\section{References}

[1] D. Wei, A. Ivaska, Applications of ionic liquids in electrochemical sensors, Anal. Chim. Acta. 607 (2008) 126-135.

[2] M.J.A. Shiddiky, A.A.J. Torriero, Application of ionic liquids in electrochemical sensing systems, Biosens. Bioelectron. 26 (2011) 1775-1787.

[3] L.E. Barrosse-Antle, A.M. Bond, R.G. Compton, A.M. O'Mahony, E.I. Rogers, D.S. Silvester, Voltammetry in room temperature ionic liquids: Comparisons and contrasts with conventional electrochemical solvents., Chem. - An Asian J. 5 (2010) 202-230.

[4] D.S. Silvester, E.I. Rogers, R.G. Compton, Reference electrodes for use in RTILs, in: F. Endres, A. Abbott, D.R. MacFarlane (Eds.), Electrodeposition from lonic Liquids, Wiley-VCH, 2008.

[5] D. Giovanelli, M.C. Buzzeo, N.S. Lawrence, C. Hardacre, K.R. Seddon, R.G. Compton, Determination of ammonia based on the electro-oxidation of hydroquinone in dimethylformamide or in the room temperature ionic liquid, 1-ethyl-3- methylimidazolium bis(trifluoromethylsulfonyl)imide, Talanta. 62 (2004) 904-911.

[6] M.A.G. Zevenbergen, D. Wouters, V.A.T. Dam, S.H. Brongersma, M. Crego-Calama, Electrochemical sensing of ethylene employing a thin ionic-liquid layer, Anal. Chem. 83 (2011) 6300-6307.

[7] B. Shvartsev, G. Cohn, H. Shasha, R.-A. Eichel, Y. Ein-Eli, Reference electrode assembly and its use in the study of fluorohydrogenate ionic liquid silicon electrochemistry, Phys. Chem. Chem. Phys. 15 (2013) 17837.

[8] A.A.J. Torriero, J. Sunarso, P.C. Howlett, Critical evaluation of reference systems for voltammetric measurements in ionic liquids, Electrochim. Acta. 82 (2012) 60-68.

[9] E.I. Rogers, D.S. Silvester, D.L. Poole, L. Aldous, C. Hardacre, R.G. Compton, Voltammetric characterization of the ferrocene vertical bar ferrocenium and cobaltocenium vertical bar cobaltocene redox couples in RTILs, J. Phys. Chem. C. 112 (2008) 2729-2735.

[10] C. Fu, L. Aldous, E.J.F. Dickinson, N.S.A. Manan, R.G. Compton, Volatilisation of ferrocene from ionic liquids: kinetics and mechanism, Chem. Commun. 47 (2011) 7083-7085.

[11] T. Kakiuchi, T. Yoshimatsu, N. Nishi, New class of $\mathrm{Ag} / \mathrm{AgCl}$ electrodes based on hydrophobic ionic liquid saturated with $\mathrm{AgCl}$, Anal. Chem. 79 (2007) 7187-7191.

[12] E.I. Rogers, D.S. Silvester, S.E.W. Jones, L. Aldous, C. Hardacre, A.J. Russell, S.G. Davies, R.G. Compton, Electrochemical kinetics of $\mathrm{Ag} \mid \mathrm{Ag}+$ and $\mathrm{TMPD}_{\mathrm{TMPD}}{ }^{+}$in the room-temperature ionic liquid [ $\left.\mathrm{C}_{4} \mathrm{mpyrr}\right]\left[\mathrm{NTf}_{2}\right]$; toward optimizing reference electrodes for voltammetry in RTILs, J. Phys. Chem. C. 111 (2007) 13957-13966.

[13] B. Huber, B. Roling, Development of a $\mathrm{Ag} / \mathrm{Ag}^{+}$micro-reference electrode for electrochemical measurements in ionic liquids, Electrochim. Acta. 56 (2011) 6569-6572.

[14] G.A. Snook, A.S. Best, A.G. Pandolfo, A.F. Hollenkamp, Evaluation of a $\mathrm{Ag} \mid \mathrm{Ag}^{+}$reference electrode for use in room temperature ionic liquids, Electrochem. Commun. 8 (2006) 14051411.

[15] C. Horwood, M. Stadermann, Evaluation of a $\mathrm{Ag} / \mathrm{Ag}_{2} \mathrm{~S}$ reference electrode with long-term stability for electrochemistry in ionic liquids, Electrochem. Commun. 88 (2018) 105-108.

[16] C. Bonnaud, I. Billard, N. Papaiconomou, E. Chainet, J.C. Leprêtre, Rationale for the implementation of reference electrodes in ionic liquids, Phys. Chem. Chem. Phys. 18 (2016) 8148-8157.

[17] P. Yager, T. Edwards, E. Fu, K. Helton, K. Nelson, M.R. Tam, B.H. Weigl, Microfluidic diagnostic technologies for global public health, Nature. 442 (2006) 412-418. 
[18] J. Lee, D.W.M. Arrigan, D.S. Silvester, Achievement of prolonged oxygen detection in room temperature ionic liquids on mechanically polished platinum screen-printed electrodes, Anal. Chem. 88 (2016) 5104-5111.

[19] A.K. Padhi, K.S. Nanjundaswamy, J.B. Goodenough, Phospho-olivines as positive-electrode materials for rechargeable lithium batteries, J. Electrochem. Soc. 144 (1997) 1188.

[20] J. Wandt, P. Jakes, J. Granwehr, R.A. Eichel, H.A. Gasteiger, Quantitative and time-resolved detection of lithium plating on graphite anodes in lithium ion batteries, Mater. Today. 21 (2017) 231-240.

[21] J. Wandt, P. Jakes, J. Granwehr, H.A. Gasteiger, R.-A. Eichel, Singlet oxygen formation during the charging process of an aprotic lithium-oxygen battery, Angew. Chemie Int. Ed. 55 (2016) 6892-6895.

[22] Y. Ishige, S. Klink, W. Schuhmann, Intercalation compounds as inner reference electrodes for reproducible and robust solid-contact ion-selective electrodes, Angew. Chemie - Int. Ed. 55 (2016) 4831-4835.

[23] F. La Mantia, C.D. Wessells, H.D. Deshazer, Y. Cui, Reliable reference electrodes for lithium-ion batteries, in: Electrochem. Commun., Elsevier B.V., 2013: pp. 141-144.

[24] S. Klink, E. Madej, E. Ventosa, A. Lindner, W. Schuhmann, F. La Mantia, The importance of cell geometry for electrochemical impedance spectroscopy in three-electrode lithium ion battery test cells, Electrochem. Commun. 22 (2012) 120-123.

[25] R.R. Gagne, C.A. Koval, G.C. Lisensky, Ferrocene as an internal standard for electrochemical measurements, Inorg. Chem. 19 (1980) 2854-2855.

[26] J. Lee, K. Murugappan, D.W.M. Arrigan, D.S. Silvester, Oxygen reduction voltammetry on platinum macrodisk and screen-printed electrodes in ionic liquids: Reaction of the electrogenerated superoxide species with compounds used in the paste of Pt screen-printed electrodes?, Electrochim. Acta. 101 (2013) 158-168.

[27] K. Yamamoto, D.M. Kolb, R. Kötz, G. Lehmpfuhl, Hydrogen adsorption and oxide formation on platinum single crystal electrodes, J. Electroanal. Chem. 96 (1979) 233-239.

[28] W.A. Henderson, S. Passerini, Phase behavior of ionic liquid-LiX mixtures: Pyrrolidinium cations and TFSI ${ }^{-}$anions - Linking structure to transport properties, Chem. Mater. 16 (2004) 2881-2885.

[29] I. Džidić, P. Kebarle, Hydration of the alkali ions in the gas phase. Enthalpies and entropies of reactions $\mathrm{M}^{+}\left(\mathrm{H}_{2} \mathrm{O}\right)_{n-1}+\mathrm{H}_{2} \mathrm{O}=\mathrm{M}^{+}\left(\mathrm{H}_{2} \mathrm{O}\right)_{n}$, J. Phys. Chem. 74 (1970) 1466-1474.

[30] C.J. Allen, J. Hwang, R. Kautz, S. Mukerjee, E.J. Plichta, M. A. Hendrickson, K.M. Abraham, Oxygen reduction reactions in ionic liquids and the formulation of a general ORR mechanism for Li-air batteries, J. Phys. Chem. C. 116 (2012) 20755-20764.

[31] K. Kubota, S. Komaba, Review-Practical issues and future perspective for Na-ion batteries, J. Electrochem. Soc. 162 (2015) A2538-A2550.

[32] J. Wandt, C. Marino, H.A. Gasteiger, P. Jakes, R.-A. Eichel, J. Granwehr, Operando electron paramagnetic resonance spectroscopy - formation of mossy lithium on lithium anodes during charge/discharge cycling, Energy Environ. Sci. 8 (2015) 1358-1367.

[33] D. Gordon, M.Y. Wu, A. Ramanujapuram, J. Benson, J.T. Lee, A. Magasinski, N. Nitta, C. Huang, G. Yushin, Enhancing cycle stability of lithium iron phosphate in aqueous electrolytes by increasing electrolyte molarity, Adv. Energy Mater. 6 (2016) 1-11. 